\title{
Effect of caffeic acid phenethyl ester on bone formation in the expanded inter-premaxillary
}

\section{suture}

\author{
Hakki Oguz Kazancioglu' \\ Sertac Aksakalli² \\ Seref Ezirganli' \\ Muhammet Birlik ${ }^{2}$ \\ Mukaddes Esrefoglu ${ }^{3}$ \\ Ahmet Hüseyin Acar ${ }^{1}$ \\ 'Department of Oral and \\ Maxillofacial Surgery, ${ }^{2}$ Department of \\ Orthodontics, Faculty of Dentistry, \\ ${ }^{3}$ Department of Histology, Faculty of \\ Medicine, Bezmialem Vakif University, \\ Istanbul, Turkey
}

Correspondence: Hakki Oguz

Kazancioglu

Department of Oral and Maxillofacial Surgery, Faculty of Dentistry, Bezmialem Vakif University, Adnan Menderes Bulvarı, 34093 Fatih, Istanbul, Turkey

Tel $+90212453 \quad 700$

Fax +902125332326

Email dt_oguz@yahoo.com
This article was published in the following Dove Press journal:

Drug Design, Development and Therapy

21 December 2015

Number of times this article has been viewed

Background: Narrow maxilla is a common problem in orthodontics and dentofacial orthopedics. To solve this problem, a procedure called rapid maxillary expansion (RME) has been used. However, relapse tendency is a major problem of RME. Although relapse tendency is not clearly understood, various treatment procedures and new applications have been investigated. The present study aimed to investigate the possible effectiveness of caffeic acid phenethyl ester (CAPE) on new bone formation in rat midpalatal suture after RME.

Materials and methods: Twenty male Sprague Dawley rats were used in this study. The animals were randomly divided into two groups as control and CAPE group. In the CAPE group, CAPE was administered systemically via intraperitoneal injection. RME procedure was performed on all animals. For this purpose, the springs were placed on the maxillary incisors of rats and activated for 5 days. After then, the springs were removed and replaced with short lengths of rectangular retaining wire for consolidation period of 15 days. At the end of the study, histomorphometric analysis was carried out to assess new bone formation.

Results: New bone formation was significantly greater in the CAPE group than the control group $(P<0.05)$. CAPE enhances new bone formation in midpalatal suture after RME.

Conclusion: These results show that CAPE may decrease the time needed for retention.

Keywords: rapid maxillary expansion, bone formation, caffeic acid phenethyl ester, midpalatal suture, histopathology

\section{Introduction}

Narrow maxilla is a common problem in orthodontics and dentofacial orthopedics. A variety of reasons, such as the narrowed nasal airway, environmental, genetic, and iatrogenic factors (eg, scar tissue due to previous surgery) can cause this problem. ${ }^{1}$ Narrow maxilla may adversely affect a person's life due to esthetic and functional impairment. ${ }^{2}$ To solve this problem, a procedure called rapid maxillary expansion (RME) has been used since the $1860 \mathrm{~s}^{3}{ }^{3}$ The aim of this procedure is to provide separation of midpalatal suture by applying significant force through the appliances. This application leads to expanding in the transverse width of maxilla. ${ }^{4}$ Nowadays, RME has become a common procedure to treat narrow maxilla. However, relapse tendency is a major problem of RME. Although relapse tendency is not clearly understood, various treatment procedures and new applications have been investigated..$^{1-4}$

Regulation of bone metabolism and retention period may be a potential key determinant for preventing relapse tendency. ${ }^{5}$ Therefore researchers focus on new materials that increase bone metabolism to reduce new bone formation period. It has also been stated that inhibition of bone resorption is crucial for preventing relapse tendency. In the 
literature, there are many articles about various materials and applications such as antioxidants, concentrated platelets, vitamins, low laser therapy, and low-intensity pulsed ultrasound that increase new bone formation. ${ }^{5-9}$

Caffeic acid phenethyl ester (CAPE), a lipid-soluble compound derived from the extract of propolis made by honeybees, is a phenolic antioxidant. CAPE has been shown to have anti-inflammatory, cytostatic, antitumor, antiviral, antibacterial, antifungal, and antimicrobial properties. ${ }^{10-12}$ Various studies have shown that CAPE has a positive effect on wound healing. ${ }^{13,14}$ It has also been stated that CAPE inhibits osteoclastic activity and enhances new bone formation. ${ }^{12,14}$ Although the healing effect of CAPE on bone defects has been investigated in few studies, ${ }^{12-14}$ there is no study to date about CAPE and prevention of relapse tendency after RME. Therefore the aim of the current study is to investigate the effects of CAPE on new bone formation in expanded suture to reduce the retention time.

\section{Methods}

\section{Sample}

In the current study 20, 3-month-old male rats (Sprague Dawley rats), weighing $222.76 \pm 18.44$ g, were used. Rats were obtained from Department of Experimental Animals, Research and Development Center of Bezmialem Vakif University. Experimental procedures of this study were approved by the Institutional Review Board and Animal Use Committee of the Bezmialem Vakif University (protocol no =2013/107). We obeyed the principles of Basel Declaration 2010. The rats were housed separately in a room under same conditions $\left(25^{\circ} \mathrm{C}, 1\right.$ atmospheric pressure, and 12-hour light/dark cycle). All animals had free access to water and food.

\section{Synthesis and dose of CAPE}

Previously, the synthesis technique of CAPE was reported by Yilmaz et al. ${ }^{15}$ Ready-made CAPE (Sigma-Aldrich, St Louis, MO, USA) was dissolved in absolute ethanol and further dilutions were made in saline. The systemic application dose of CAPE was chosen on the basis of the Grunberger et $\mathrm{al}^{16}$ study.

\section{Experimental design}

Twenty rats were randomly divided into two groups including the control and study group. Each group had ten animals. In the control group only expansion was performed. In the study group, expansion was performed and rats intraperitoneally (ip) received CAPE with a dose of $10 \mathrm{mmol} / \mathrm{kg} /$ day during the time of study.

\section{Placement of appliances}

Before the insertion of the expansion appliance, the rats were anesthetized by intramuscular injection of $3 \mathrm{mg} / \mathrm{kg}$ xylazine hydrochloride and $35 \mathrm{mg} / \mathrm{kg}$ ketamine hydrochloride. Following the induction of general anesthesia, a helical spring fabricated wire, a 0.012 inch piece of stainless steel wire, were used for expansion (Figure 1A). The springs were activated using pliers and application force was adjusted to be $30 \mathrm{~g}$. The groove was conduct at the level of the gingival papilla on the maxillary incisor teeth for obtain retention. After that, a stainless steel ligature with a size of 0.009 inch was used to fix the spring. These procedures were performed on both control and study group.

The helix springs were activated to expand the maxilla with a force of $30 \mathrm{cN}$ for 5 days. Expansion period was terminated after 5 days later. A distance of $1.5 \mathrm{~mm}$ was provided between maxillary incisors at the end of the expansion period. After expansion period, the springs were removed and short lengths of rectangular retaining wire replaced for consolidation period of 15 days period (Figure 1B).

\section{Histological analysis}

Twenty animals were sacrificed at the end of the study with an overdose of $200 \mathrm{mg} / \mathrm{kg}$ intravenous (IV) pentobarbital (Pentothal, Abbott Laboratories, Abbott Park, IL, USA). Premaxillae of the rats were dissected out and fixed in $10 \%$ neutral formalin for 5 days. After fixation, the premaxillae was rinsed with water to remove the formaldehyde and calcified in $10 \%$ formic acid at room temperature for 5 days. Every day the formic acid solution was renewed. After decalcification, two tissue samples were obtained from each animal. One sample was obtained from the incisors at the alveolar crest and perpendicular to the sagittal plane, the other sample was obtained $4 \mathrm{~mm}$ apical to the first one. Then the specimens obtained from the rats were embedded in paraffin blocks. From the paraffin blocks, cross-sections with a thicknesses of $5 \mu \mathrm{m}$ were prepared using a microtome. The sections were stained with hematoxylin-eosin (HE). Histologic and histomorphometric analysis were performed around the premaxillary suture under a light microscope (Nikon, DS-Fi1c, Tokyo, Japan). To ensure standardization, the area selected was between the two straights, the first straight was at the beginning of the incisors and the second straight was $2.5 \mathrm{~mm}$ from the beginning straight (Figure 2). Afterward, the regenerated new bone area $\left(\mathrm{mm}^{2}\right)$ and percentage of new bone formation were calculated using the NIS Elements version 4.0 image 

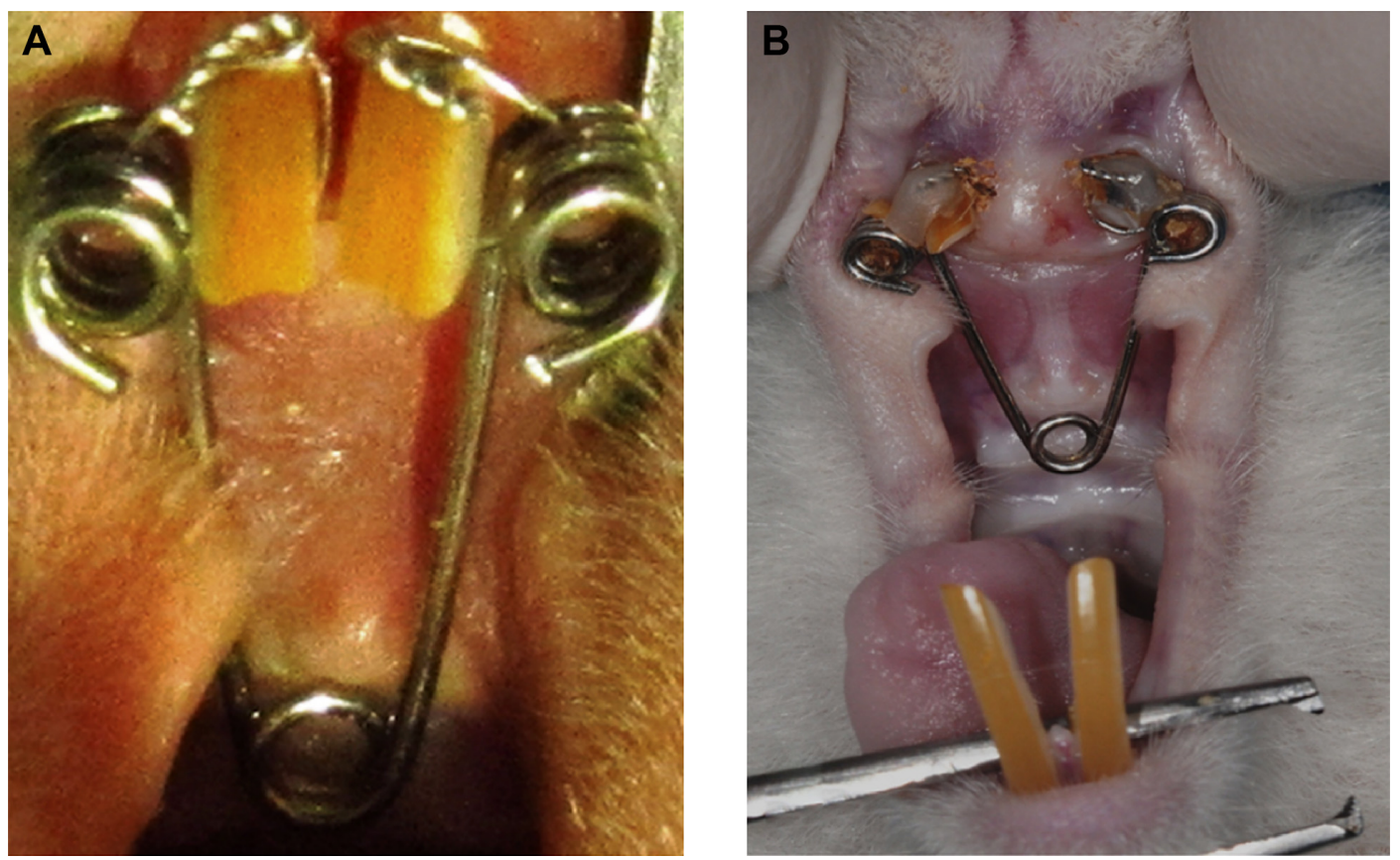

Figure I The expansion appliance and expanded suture.

Note: (A) Placement of the expansion appliance; (B) expanded interpremaxillary suture.

analysis system (Nikon Instruments Inc., Tokyo, Japan) in the expanded suture area with an original magnification of $\times 40$ on the fluorescent images (Figures 3 and 4).

\section{Statistical analysis}

The software program SPSS Statistical Package for Social Sciences (SPSS for Windows 15.0; SPSS Inc., Chicago, IL, USA) was used for statistical analyses. The Mann-Whitney $U$-test was used for intergroup comparison of parameters. Statistics were given as quartiles (25th, 50th - median, and 75th), minimum (Min), and maximum (Max). Results were considered significant at the level of $P<0.05$.

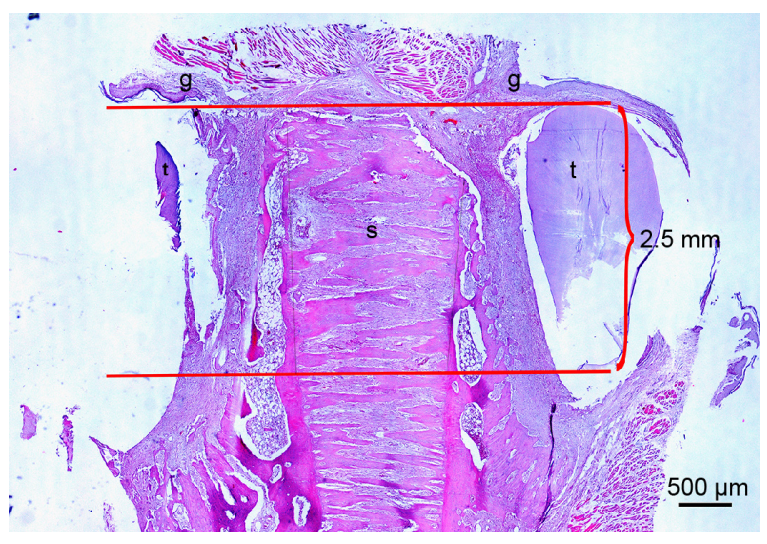

Figure 2 Histomorphometric image of the expanded inter-premaxillary suture. Notes: Two straights were determined on the suture area. One of the straights was at the beginning of the incisors and the other was $2.5 \mathrm{~mm}$ from the first straight. Abbreviations: g, gingiva; s, suture area; $t$, tooth.

\section{Results}

At the end of the study maxillary expansion was successfully performed. Also, rats tolerated the expansion of the midpalatal suture. There were no adverse effects observed, such as neurological symptoms, weight loss, dehiscence, inflammation, and mucosal trauma. However, two animals were excluded from study due to appliance failure. They were replaced with two other rats. The inter-premaxillary suture was successfully expanded following application of the activated helical spring. Comparisons of new bone areas among the groups are shown in Table 1. The percentages of newly formed bone (new bone area ratio to suture area) and new bone area were significantly greater in the study group when compared to the control group.

\section{Discussion}

Various animal species are used for evaluation of bone healing in the studies. However; small animal models are more frequently used than larger animals because they are more cost efficient, easier to handle, and due to ethical issues. Rats and rabbits are appropriate animals for investigations on sutural tissues. ${ }^{17}$ In the current study, we used rats as their care and the application of RME is easier than rabbits.

There are various techniques such as histomorphometry, immunohistochemical, and radiological methods to investigate bone formation. Histomorphometric analysis, considered the gold standard to evaluate bone formation, is 

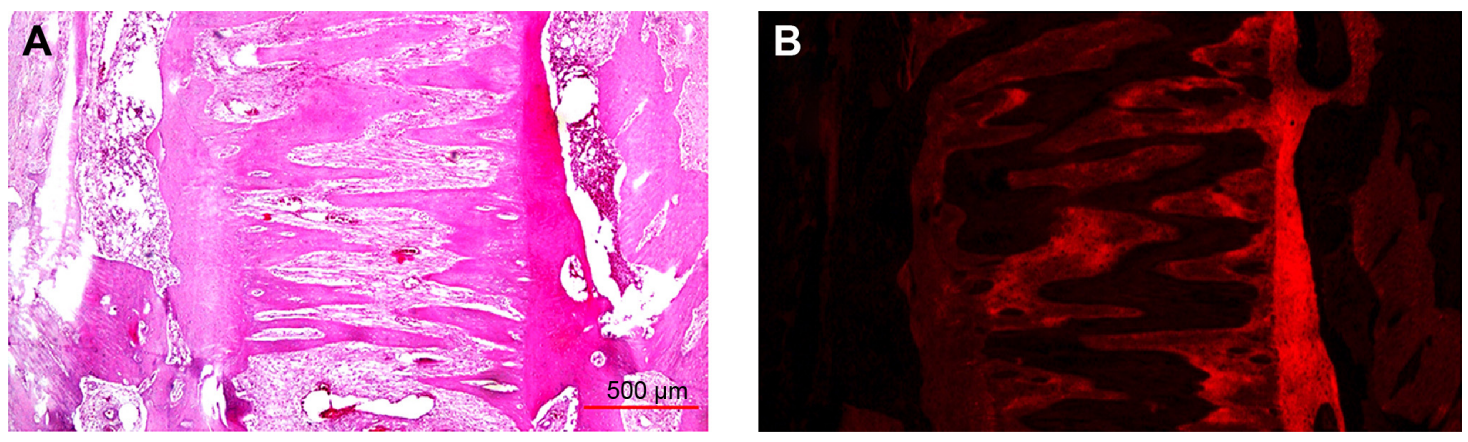

Figure 3 (A) Photomicrograph of a section in the expansion area of CAPE group showing larger masses of new bone trabeculae. (B) Immunofluorescence analysis of tissues in the CAPE group.

Note: (A) New bone attached to old bone at the site of expansion. The large areas of new bone formation indicate the later stages of bone formation (HE $\times 400$ magnification).

Abbreviations: CAPE, caffeic acid phenethyl ester; HE, hematoxylin-eosin.

the only technique that provides the opportunity to perform an in situ analysis of bone metabolism and cellular activity. ${ }^{18,19}$ Because histomorphometry is a more effective technique than the other methods, we used this method for new bone formation evaluation in midpalatal suture in the current study. In this study, we calculated percentages of newly formed bone because it has been shown that calculation of percentages of newly formed bone is a reliable method of showing bone regeneration. ${ }^{8,9}$

Expansion period is an important issue of the RME. It has been stated that a 5-day expansion period is enough to perform a space in rats on midpalatal suture. ${ }^{3}$ Therefore, we performed the RME appliance for 5 days. After the expansion period, a space between the mesial corners of the maxillary incisors occurred. Furthermore, required amount of space in the midpalatal suture was observed by a histologist during histomorphometric evaluation.

Relapse tendency after RME is a common problem in orthodontics. To solve this problem many applications have been used in studies. ${ }^{5-7}$ However, many of them are not suitable for clinical use. Nowadays, there is a growing interest

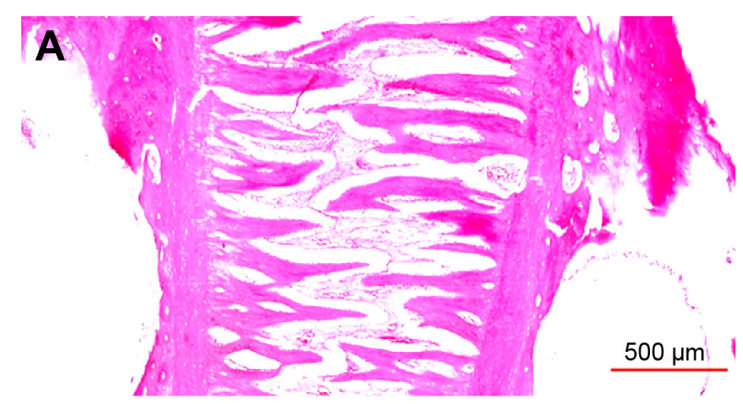

for natural health products. CAPE, an active component of honeybee propolis, is a completely natural product. Propolis has been used for wounds since ancient times due to its anti-inflammatory and antimicrobial properties that accelerate wound healing. ${ }^{11,20} \mathrm{CAPE}$ was extracted from propolis by Grunberger et $\mathrm{al}^{16}$ in 1988 for the first time in its history. It has been stated that CAPE may accelerate wound healing. This property may be associated with antioxidant and anti-inflammatory effects. Inflammatory mediator and histamine may negatively affect wound healing process. ${ }^{21}$ Several studies have shown that CAPE has antioxidant and anti-inflammatory effects. ${ }^{22,23}$ CAPE exhibits its antiinflammatory effects by inhibition the cyclooxygenase and lipoxygenase pathways and this causes inhibition production of leukotriene and prostaglandin. ${ }^{24}$ Song et al ${ }^{13}$ stated that CAPE, acts as an anti-inflammatory, and inhibits histamine release and prostaglandin E2 production. Serarslan et al ${ }^{25}$ reported that CAPE accelerates full-thickness wound healing by decreased oxidative stress.

CAPE may also enhance the wound healing process via fibroblast activity. Fibroblasts have a critical role in initial

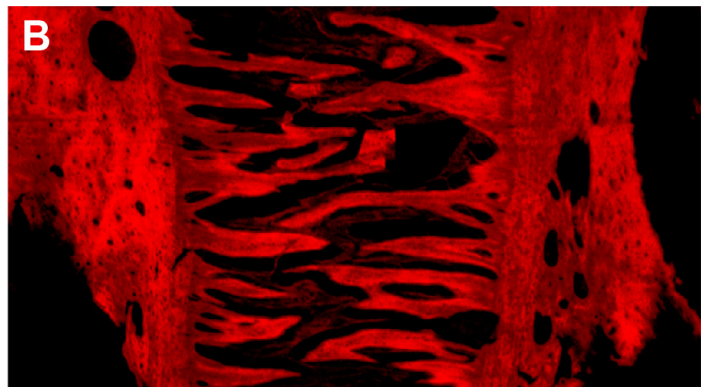

Figure 4 (A) Photomicrograph of a section in the expansion area of control group showing abundant formation of bone trabeculae. (B) Immunofluorescence detection of tissues in control group.

Note: (A) The large amounts of connective tissue indicate the beginning stages of bone formation ( $\mathrm{HE} \times 400$ magnification).

Abbreviation: HE, hematoxylin-eosin. 
Table I Results and statistical comparisons of biometric analysis for determination of expansion

\begin{tabular}{lllllllll}
\hline Parameters & Group & $\mathbf{n}$ & Min & Max & $\mathbf{2 5 \%}$ & Median & $\mathbf{7 5 \%}$ & P-value \\
\hline Area investigated $\left(\mu \mathrm{m}^{2}\right)$ & Control & 10 & 101.21 & 150.15 & 105.95 & 132.24 & 155.4 & 0.011 \\
& CAPE & 10 & 131.82 & 192.75 & 136.05 & 155.39 & 171.41 & 45.13 \\
Newly formed bone $(\%)$ & Control & 10 & 40.12 & 44.16 & 41.83 & 44.85 & 40.011 \\
& CAPE & 10 & 43.96 & 55.57 & 45.66 & 49.91 & 53.86 & \\
\hline
\end{tabular}

Abbreviations: CAPE, caffeic acid phenethyl ester; Max, maximum; Min, minimum; n, sample size.

stages of the wound healing process, increasing the number of fibroblasts improves tissue repair. ${ }^{26}$ Song et a ${ }^{13}$ reported that CAPE increase collagen-like polymer levels secreted by fibroblasts.

It has been shown that CAPE may reduce bone resorption via inhibition of the activity of nuclear factor of activated T-cells. ${ }^{12}$ Also, it has been stated that CAPE induces osteoclast apoptosis. ${ }^{23,27} \mathrm{Ha}$ et $\mathrm{al}^{28}$ reported that CAPE may be used for the treatment of bone destructive diseases, due to its inhibition effect on receptor activator nuclear factor- $\mathrm{\kappa B}$ ligand that are key molecules for activation of osteoclasts. Ang et $\mathrm{al}^{29}$ stated that CAPE inhibits osteoclastogenesis and induces apoptosis through the suppression of nuclear factor of activated T-cells activation, and receptor activator nuclear factor- $\mathrm{\kappa B}$ ligand-induced osteoclast formation. Therefore researchers suggest that CAPE may be used in pathological bone diseases..$^{27,28}$ However, there is only one paper ${ }^{30}$ that has found the effects of CAPE on bone defect healing in the English literature. It has been found that CAPE enhances new bone formation in rat calvarial defect. To the best of our knowledge, the current study is the first published paper in the English literature that investigates new bone formation effects of CAPE in midpalatal suture after RME; and according to current study results, CAPE enhance new bone formation in rat suture after RME.

Application methods and dose of CAPE are important for the treatment of bone healing. It was reported that dose of $100 \mathrm{mmol} / \mathrm{kg}$ CAPE topical application was more effective than dose of $50 \mathrm{mmol} / \mathrm{kg}$ CAPE for new formation in rats calvarial defects. It also has been stated that intraperitoneal injection of CAPE is more effective than local application. ${ }^{30}$ Therefore in our study, we used CAPE with systemic application.

In conclusion, systemic application of CAPE enhances new bone formation in rat midpalatal suture after RME. We believe that CAPE may be used as a therapeutic agent for reducing the required retention time. Also, CAPE is completely natural and has no side effects. However, this being an animal study, a clinical study should be performed, and therapeutic dose of CAPE should be determined.

\section{Acknowledgment}

This work was supported by the Scientific Research Project Fund of Bezmialem Vakif University under project number 2013/107.

\section{Disclosure}

The authors report no conflicts of interest in this work.

\section{References}

1. Proffit WR. Contemporary Orthodontics. St Louis, MO: Mosby; 1986.

2. Pirelli P, Saponara M, Guilleminault C. Rapid maxillary expansion in children with obstructive sleep apnea syndrome. Sleep. 2004;27(4): 761-766.

3. Angell EC. Treatment of irregularities of the permanent or adult teeth. Dental Cosmos. 1860;1:540-544.

4. McNamara JA, Brudon WL. Orthodontics and Dentofacial Orthopedics. Ann Arbor, MI: Needham Press; 1995.

5. Altan BA, Kara IM, Nalcaci R, et al. Systemic propolis stimulates new bone formation at the expanded suture: a histomorphometric study. Angle Orthod. 2013;83(2):286-291.

6. Uysal T, Amasyali M, Enhos S, Sonmez MF, Sagdic D. Effect of ED-71, a new active vitamin D analog, on bone formation in an orthopedically expanded suture in rats. A histomorphometric study. Eur J Dent. 2009;3(3):165-172.

7. da Silva AP, Petri AD, Crippa GE, et al. Effect of low-level laser therapy after rapid maxillary expansion on proliferation and differentiation of osteoblastic cells. Lasers Med Sci. 2012;27(4):777-783.

8. Acar AH, Yolcu Ü, Gül M, Keleş A, Erdem NF, Altundag Kahraman S. Micro computed tomography and histomorphometric analysis of the effects of platelet-rich fibrin on bone regeneration in the rabbit calvarium. Arch Oral Biol. 2015;60(4):606-614.

9. Acar AH, Yolcu Ü, Altındiş S, Gül M, Alan H, Malkoç S. Bone regeneration by low-level laser therapy and low-intensity pulsed ultrasound therapy in the rabbit calvarium. Arch Oral Biol. 2015;61: 60-65.

10. Pascual C, Gonzales R, Torricella RG. Scavenging action of propolis extract agents oxygen radicals. J Ethnopharmacol. 1994;41(1-2): 9-13.

11. Dobrowolski JW, Wohoraq SB, Sharma K, Shah SA, Naqvi SA, Dandiya PC. Antibacterial, antifungal, antiamoebic, anti-inflammatory, and antipyretic studies on propolis bee products. J Ethnopharmacol. 1991; 35(1):77-82.

12. Erdem M, Gulabi D, Sen C, Sahin SA, Bozdag E. Effects of caffeic acid phenethyl ester and melatonin on distraction osteogenesis: an experimental study. Springerplus. 2014;3(8).

13. Song HS, Park TW, Sohn UD, et al. The effect of caffeic acid on wound healing in skin-incised mice. Korean J Physiol Pharmacol. 2008; 12(6):343-347.

14. Kınıs V, Ozbay M, Akdag M, et al. Effects of caffeic acid phenethyl ester on wound healing of nasal mucosa in the rat: an experimental study. Am J Otolaryngol. 2014;35(4):482-486. 
15. Yilmaz HR, Uz E, Altunbasak A, Sakalli E, Ozçelik N. Anticlastogenic effect of caffeic acid phenethyl ester on cisplatin-induced chromosome aberrations in rat bone marrow cells. Toxicol Ind Health. 2010;26(1):33-37.

16. Grunberger D, Banerjee R, Eisinger K, et al. Preferential cytotoxicity on tumor cells by caffeic acid phenethyl ester isolated from propolis. Experientia. 1988;44(3):230-232.

17. Saito S, Shimizu N. Stimulatory effects of low-power laser irradiation on bone regeneration in midpalatal suture during expansion in the rat. Am J Orthod Dentofacial Orthop. 1997;111(5):525-532.

18. Iwaniec UT, Wronski TJ, Turner RT. Histological analysis of bone. Methods Mol Biol. 2008;447:325-341.

19. Kulak CA, Dempster DW. Bone histomorphometry: a concise review for endocrinologists and clinicians. Arq Bras Endocrinol Metabol. 2010;54(2):87-98.

20. Günay A, Arpağ OF, Atilgan S, Yaman F, Atalay Y, Acikan I. Effects of caffeic acid phenethyl ester on palatal mucosal defects and tooth extraction sockets. Drug Des Devel Ther. 2014;23(8):2069-2074.

21. Mills TA, Taggart MJ, Greenwood SL, Baker PN, Wareing M. Histamine-induced contraction and relaxation of placental chorionic plate arteries. Placenta. 2007;28(11-12):1158-1164.

22. Natarajan K, Singh S, Burke TR Jr, Grunberger D, Aggarwal BB. Caffeic acid phenethyl ester is a potent and specific inhibitor of activation of nuclear transcription factor NF-kappa B. Proc Natl Acad Sci US A. 1996;93(17):9090-9095.

23. Hung MW, Shiao MS, Tsai LC, Chang GG, Chang TC. Apoptotic effect of caffeic acid phenethyl ester and its ester and amide analogues in human cervical cancer ME180 cells. Anticancer Res. 2003;23: $4773-4780$.
24. Mirzoeva OK, Calder PC. The effect of propolis and its components on eicosanoid production during the inflammatory response. Prostaglandins Leukot Essent Fatty Acids. 1996;55(6):441-449.

25. Serarslan G, Altuğ E, Kontas T, Atik E, Avci G. Caffeic acid phenethyl ester accelerates cutaneous wound healing in a rat model and decreases oxidative stress. Clin Exp Dermatol. 2007;32(6):709-715.

26. Lamme EN, Van Leeuwen RTJ, Brandsma K, Van Marle J, Middelkoop E. Higher numbers of autologous fibroblasts in an artificial dermal substitute improves tissue regeneration and modulates scar tissue formation. J Pathol. 2000;190(5):595-603.

27. McEleny K, Coffey R, Morrissey C, Fitzpatrick JM, Watson RW. Caffeic acid phenethyl ester-induced PC-3 cell apoptosis is caspase-dependent and mediated through the loss of inhibitors of apoptosis proteins. BJU Int. 2004;94(3):402-406.

28. Ha J, Choi HS, Lee Y, Lee ZH, Kim HH. Caffeic acid phenethyl ester inhibits osteoclastogenesis by suppressing NF kappaB and downregulating NFATc1 and c-Fos. Int Immunopharmacol. 2009;9(6):774-780.

29. Ang ES, Pavlos NJ, Chai LY, et al. Caffeic acid phenethyl ester, an active component of honeybee propolis attenuates osteoclastogenesis and bone resorption via the suppression of RANKL-induced NF-kappaB and NFAT activity. J Cell Physiol. 2009;221(3):642-649.

30. Kazancioglu HO, Bereket MC, Ezirganli S, Aydin MS, Aksakalli S. Effects of caffeic acid phenethyl ester on wound healing in calvarial defects. Acta Odontol Scand. 2015;73(1):21-27.
Drug Design, Development and Therapy

\section{Publish your work in this journal}

Drug Design, Development and Therapy is an international, peerreviewed open-access journal that spans the spectrum of drug design and development through to clinical applications. Clinical outcomes, patient safety, and programs for the development and effective, safe, and sustained use of medicines are a feature of the journal, which

\section{Dovepress}

has also been accepted for indexing on PubMed Central. The manuscript management system is completely online and includes a very quick and fair peer-review system, which is all easy to use. Visit http://www.dovepress.com/testimonials.php to read real quotes from published authors. 